\title{
An Analysis on History and Cultural Background of Chinese Tai Chi Soft Ball 太極柔力球蓮動的歴史文化分析
}

\author{
En-jing LI $^{1,2}$ Michael Huen-sum LAM ${ }^{3,4}$ \\ Lobo LOUIE $^{4}$ Sam Sai-sum LI $^{5}$
}

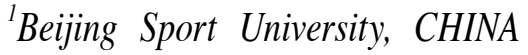

${ }^{2}$ Department of Physical Education,

Central China Normal University, Wuhan, CHINA

${ }^{3}$ Faculty of Medicine, The University of Hong Kong, HONG KONG

${ }^{4}$ Department of Physical Education, Hong Kong Baptist University, HONG KONG

${ }^{5}$ The Technological and Higher Education Institute of Hong Kong, HONG KONG

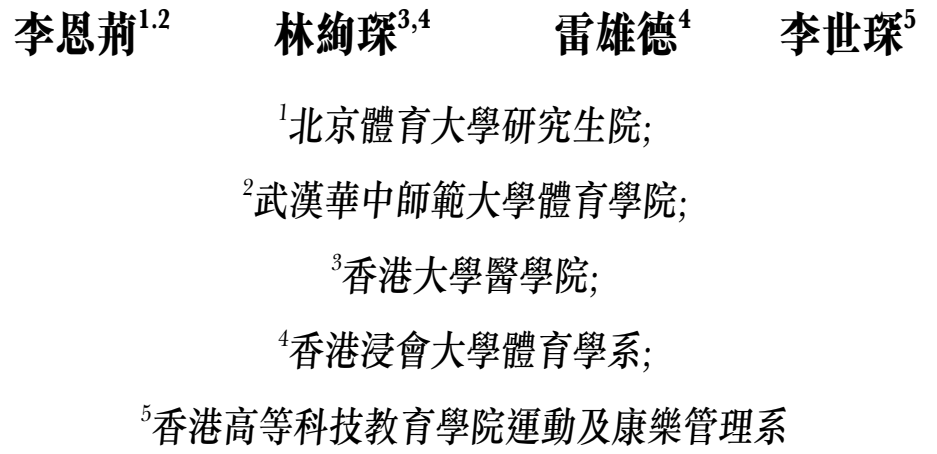

摘 要

太極柔力球是一項由中國人發明的, 具有深厚文化內涵和哲理, 融傳統（太極）運動方式與現代競技雙重特徵於一體，具有 鮮明民族特色的新興體育運動項目。太極柔力球運動的產生正是受到中國傳統文化的深刻影響, 才能在短短的 20 年時間裡成井噴 式發展, 並為世界各國人民所喜愛。此文章全面研究太極柔力球運動產生的歷史文化背景, 以及有系統地回顧世界各地太極柔力 球運動的循證研究, 為這一既古老又年輕運動的發展尋找更加堅實的理論基礎。

關鍵字：太極柔力球；產生；文化背景；循證研究；系統性回顧

\begin{abstract}
Tai Chi Soft Ball is a young Chinese sport with distinctive ethnic characteristics. It has profound cultural connotation and philosophy, and blends traditional sport and modern competitive sport into a unity. Deeply rooted in traditional Chinese culture, the sport developed rapidly in the last 20 years, and loved by people all over the world. The aims of this paper are to provide 1) a comprehensive historical and cultural background of Tai Chi Soft Ball and; 2) a solid theoretical foundation for this ancient but young sport and; 3) systematic review on Tai Chi Soft Ball in scientific evidence based research.
\end{abstract}

Keywords: Tai Chi Soft Ball; produce; cultural background; Evidence-based research; systematic review 
太極柔力球運動是借鑒及吸取太極的理論, 並結合當代 眾多競技體育項目而發明的一項新興體育項目。在套路運動 中, 動作柔和、緩慢、輕靈、沉穩, 處處帶有弧形, 勢勢連 綿不斷。它的運動特點是心靜體松、呼吸自然, 輕靈沉著、 圓活連貫, 上下相隨、虛實分明, 柔中寓剛、以意導動。它 不僅其有良好的強身健體、防病祛病、延年益壽的功效, 而 且還其有陶冶性情、修身養性的功能以及獨其特色的技擊理 論, 因而深受廣大人民群眾所喜愛。在發明到現在短短十幾 年的時間裡, 就受到了全國各界人士的喜愛, 在老年人中每 年有固定的全國比賽, 部份大中學還開設了選修課, 它獨特 的太極理論使該項運動走進了勞教所、監獄的大門, 成為淨 化犯人思想的武器。短短時間裡就有 20 多個國家和地區的人 民參與進來。

太極柔力球運動融入了濃鬱的中國傳統文化內涵, 它 植根於傳統哲學、中醫學、兵法學、養生學、倫理學、美學 等古典文化基礎之上, 並逐漸構建了自身的文化理論體系。 太極柔力球運動在形成和發展過程中所吸收和應用的哲學思 想, 充分證明瞭中國傳統哲學的無窮魅力和奇光異彩。認識 了太極柔力球產生的的中國歷史文化背景, 就能從根本上理 解太極柔力球的文化特徵, 揭示其運動的奧妙。

\section{太極柔力球運動產生的中國歴史文化背景}

\section{1. 太極學説是太極柔力球運動形成的理論根本}

太極學説是中國古代椪素唯物主義的宇宙觀, 它內寓萬 物陰陽變化之至理, 是太極柔力球運動形成的理論根本。

“太極”一詞, 最早見於《易經・晸辭》, “易有太 極, 是生兩儀, 兩儀生四象, 四象生八卦”。“太”是大或 高的意思, “極” 是頂點的意思, “太極” 就是大的頂點或 高的頂點的意思。鄭玄注 “太極” 為: “氣象未分之時, 天地 之始也。” 唐代孔穎達解釋説: “太極謂天地未分之前, 元氣 混而為一, 即是太初, 太一也。”這裡的“太極” 是派生世 界萬事萬物的本源。太極為天地萬物之根本, 宇宙萬物之總 則。繪有太極圖的宋朝周敦頣在所著《太極圖説》中雲: “無 極而太極, 太極動而生陽。動極而靜, 靜而生陰。靜極複 動, 一動一靜互為其根。

分陰分陽, 兩儀立焉。”無極而太極, 太極動而生陰 陽, 陰陽生克而四季, 萬物而得以化生。這就是對宇宙萬 物演化過程的樸素唯物的描述。古人用一中空圓圈表示 “無 極” 天地未開, 陰陽未分之茫茫宇宙。從太極圖來看： “其 外一圈者, 太極也。中分黑自者, 陰陽也。黑中含一點自 者, 陰中有陽也; 自中含一點黑者, 陽中有陰也。陰陽互 動, 動靜相倚, 周詳活潑, 妙趣自然。”從 “太極圖” 與 “無極圖” 中我們可以看出：“無極”與 “太極”兩者都是 用一中空的圓來表示的。這就深刻揭示了宇宙的浩瀚深厚, 世界的無邊無際, 自然的博大闊遠, 萬物的無始無终。同時
也預示著 “有” 和 “無” 的對立同一, 孕育著太極的陰陽互 化。

太極柔力球的圓弧運動正是 “無極圖”與 “太極圖”圓 形的其體體現。太極柔力球的一招一勢都離不開圓, 或大圓 或小圓, 或平圓或立圓, 或圓弧, 處處圓活, 環環纏繞。這 既包含了無極之圓的渾然一體, 猶如宇宙的廣闊浩瀚、無始 無終, 又體現了太極之圓的陰陽分明、動靜相輔。這就要求 練習太極柔力球者要心胸開闊、萬念歸一、寧靜空虛, 把握 到這一點, 才會真正練好太極柔力球運動。

\section{2. “天人合一”整體觀是太極柔力球運動存在和發展 的哲學思想基碟}

“天人合一” 是中國古代哲學中的一個古老命題。張 岱年先生説: “中國哲學有一個根本觀念, 即 '天人合一”。 認為天人本來合一, 而人生最高理想, 是自覺地達到天人合 一之境界。物我本屬一體, 內外原無判隔。”( 《中閏哲學 大綱》) “天人合一” 整體觀即是：人與自然、人與社會以 及自我身心內外的和諧統一關係。簡言之, 就是講人與自然 的關係。何謂 “天”? 這是指宇宙、天地、萬物的大自然, 人應包括在內。大自然是個大宇宙, 人體是個小宇宙。“天 人合一”整體觀, 強調了“天道”與 “人道”、“自然” 與 “人” 的整體合一。儒家思想的代表人物孔子早在《論 語》中就提到 “知我者其天乎” , “五十而知天命” 的説 法。而最早最完整地提出 “天人合一”整體觀的是戰國時 期的孟子, 他説: “盡其心者, 知其性也; 知其性, 則知天 矣。”(《孟子· 盡心上》) 後來, 漢代的大儒家董仲舒認為 “天亦有喜怒之氣, 哀樂之心, 與人相副。以類合之, 天人 一也。”這種 “天人合一” 整體觀表明 : 天與人是相互感應 的, 大宇宙的變化影響到人體這個小宇宙, 而人體自身的變 化, 也可反應大自然的運行規律, 強調客觀世界與主觀世界 的和諧統一。而這種 “天人合一” 的自然與人的關係在太極 柔力球的練習中表現得淋漓盡致。

太極柔力球的練習強調在大自然中對人體身心 、內外、 形神的整體性修煉, 進而最終達到主客體相互交融的神韻, 從而得以實現人與自然 “天人合一”思想的宇宙最高境界。 太極柔力球運動的 “天人合一” 整體觀是對中國古代 “天人 合一” 哲學思想的繼承, 同時又把這種思想通過太極柔力球 這一具體形式表現出來, 並加以發展與完善。

\section{3. 陰陽學説是太極柔力球運動形成的辩證思維基礎}

陰陽是中國古代哲學的一對最基本的範疇。陰陽學説是 中國古代的一種宇宙觀和方法論, 它建立在中國古代樸素唯 物主義的哲學觀基礎之上, 內含對立統一的辯證法思想, 它 是太極柔力球運動形成的哲學辯證思維基礎。 
3.1 陰陽對稱: 即在圓形的整體之中, 包涵了兩個對稱又平衡 的黑白互回的陰陽魚。陰陽魚對稱、對立、對等而和諧地 相處於一個圓形整體之內。對稱、和諧, 既是自然界的根 本法則, 也是太極柔力球運動的最高原則。打太極柔力球 時, 應該剛柔相濟、開合相寓、虛實互換、快慢相間, 使身 心乃至肢體各組對稱的部位都得到平衡的鍛煉。即使在 勁力上, 也要講究對稱·平衡。比如: 左發右塌, 右發左塌; 前去之中必有右撑; 逢上必下, 逢左必右, 以維持自身平 衡。

3.2 陰陽互抱(互孕): 黑魚有一隻白眼睛, 白魚有一隻黑眼睛。 這象徵著陰中有陽, 陽中有陰, 陰陽交錯陰陽互根。也即 陰陽互抱, 陰陽互孕。這要求練太極柔力球時要開中有 合, 合中有開, 舒展之中有團聚之意, 緊湊之中有開展之 功。虛實、剛柔也是如此: 虛中有實, 實中有虚; 剛中有柔, 柔中有剛。

3.3 陰陽消長: 陽魚膨大的部位, 陰魚則縮小; 陰魚膨脹的部 位, 陽魚則收縮。陰陽粘隨互補, 彼消我長, 彼長我消, 陰陽互長。打太極柔力球, 特別是在太極柔力球競技比賽 中, 只有善於運用 “太極圖” 內陰與陽的彼此進退的消長 規律, 才能立於不敗之地。太極柔力球競技比賽要求對抗 者, 以已之長, 攻彼之短, 抑彼之長, 避已之短, 在戰術的 運用中, 始終要最大限度地發揮自己的優勢和特長, 找准 對方弱點或要害, 力求以長擊短。在比賽中要攻防結合, 打吊結合, 精心作好攻防動作的銜接和組合, 講究攻防 的一體性和進攻的連續性。敵進我退, 敵退我進, 以柔克 剛, 借力打力處處都體現這種陰長陽消、陽長陰消的陰陽 消長規律。

3.4 陰陽變化的螺旋形式: 陰陽魚之間漩渦狀的 “S” 型曲線 象徵著一種動態, 它標誌著事物的陰陽變化是在螺旋式 動態中變化發展的。太極柔力球所有勁力和形態動作, 處 處都要走螺旋, 即 “非圓即弧”, “非順即逆”, “非自轉即 公轉”。虚實、快慢都是在螺旋中運動、變化。打太極柔力 球不講纏絲勁, 不講立體螺旋者, 即不符合 “太極圖” 的 這一特色, 同時也練不好太極柔力球。

3.5 離心與向心狀態的統一體: 若以陰魚的眼睛為圓心, 則陰 魚體的螺旋式的作用力是向心的; 而陰魚尾所形成的作用 力則是離心的。太極柔力球向心與離心作用相反的兩種螺 旋力的和諧統一性是該運動的秘訣之一。球體之所以能粘 連撚隨在球拍上而不掉, 正是力學中向心力與離心力達到 平衡的體現。這種離心運動與向心運動相結合的運動方 式, 正好體現了“太極圖” 中陰陽互為其根的特徵。

\section{4. “合和”思想是太極柔力球運動發展的方向}

“合和” 思想是中國文化基本精神的一個構成部分, 在凝聚民族精神、激勵民族發展、整合外來文化上起到重 要作用。這一精神在太極柔力球運動中表現得尤為突出。宋 初道教學者陳搏的《太極圖》説: “其外一圈者, 太極也, 中分黑白者, 陰陽也, 黑中含一點白者, 陰中有陽, 白中含 一點黑者, 陽中有陰。陰陽交互, 動靜相倚, 周詳活潑, 妙 趣自然。” 平時所看到的只是立體太極圖的一横斷面, 若在 太極圖中畫通過圓心的一直線, 假設為太極柔力球場地的横 網, 那麼這個圖正是太極柔力球運動中球的往返路線的真實 寫照。若球在近似水平面上運動, 我們俯視看到的則是太極 圖的外圓圈。若在額狀面和矢狀面上運動, 正符合太極圖的 完整圖形。立體的太極圖模型是由大球面內的無數個小圓組 成, 或是説圓內的弧形是動態的, 無論從那個角度切開, 都 是一個完整的 “太極圖” 圖形。“合和” 思想有調和、和 諧、和平等含義, 在此項目中不單指同方隊員之間的密切配 合, 顧全大局, 尤其強調對立雙方之間的相互協調與渗透, 單獨存在那一方都不能形成完整的圓, 不能達到相互統一。 而其它項目, 無論羽毛球、網球都是單線的重複往來, 本能 地用拙力擊打來球, 形成精神、氣勢、情感的對立, 太極柔 力球運動與它們截然不同, 也是不同於眾多體育專案的獨特 之處, 是自身發展的根本源泉。

“反者道之動, 弱者道之用”。這是老子哲學中辩證法 思想的著名命題, 是説對立的事物向著反面轉化是運動的規 律, 《道德經》中講 “弱之勝強, 柔之勝剛, 天下莫不知, 莫能行。” 認為最柔的事物, 總是最能控制堅強的事物。太 極柔力球運動是這一思想的具體運用, 反對以剛克剛、拙力 回擊, 用反關節, 多角度, 間接的方式迎送、化解來球, 從 而克服急躁激進的心理, 改變過去運動意識中的發洩、猛攻 猛打、一錘定音、立竿見影的功利追求。任何事物都有正、 反兩方面因素組成, 在方法論上, 現實人們習慣的思維方 式和行為格式都在於過多地看中了 “正” 的價值, 輕視了 “反”的意義。

在太極柔力球的實踐運動中, 很多初學者在觸球時, 總 是用拍迎球擊打, 表現出本能的、自然的思維習慣和行為方 式。反向的思維在生活偶爾提起, 如 “居安思危” , “飽帶 乾糧暖穿衣”等。設想, 經常參與太極柔力球活動, 將潛意 識地影響、強化我們的思維方式, 多角度地考慮問題, 使社 會朝著更文明的方向發展。

隨著 “東學西漸” 的浪潮, 西方人們更多地膫解、甚至 在學習東方文化。《孫子兵法》、《周易》、“儒家思想” 已被西方一些企業家們吸納。薩馬蘭奇主席也曾説過：“國 際奧會主導思想應建立在洅通東西方文化的基礎上。” 如果 説武術是東方文化典型代表項目, 並有望進入奧運會, 那 麼, 太極柔力球是東西方文化交融的結晶, 是現代文明的產 物, 也應普及國內, 推向世界, 為人類文明做出貢獻。 


\section{$5 \cdot$ 結論}

太極柔力球運動是在近幾年在廣大人民群眾中廣泛流行 的運動之一，它植根於中國統文化的理論體系之中。太極柔 力球運動的產生和發展受到中國傳統哲學的深刻影響, 只有 真正體會到中國傳統哲學中的太極學説、陰陽學説、“天人 合一”整體觀和 “合和”思想的原理, 才能從根本上理解太 極柔力球運動的奧妙。

\section{太極柔力球運動循證研究系統性回顧分析}

為了了解各國太極柔力球的循證研究, 作者對太極柔 力球運動做了一系列的系統性回顧。回顧方法為一) 年期由 1960年到2011年；二) 八個國際論文集數據 庫 (Medline, PubMed, CINAHL, PsycINFO, Proquest, Sport DISCUS, ISI Web of Science and ERIC); 三) 七個主題關鍵詞語 (Tai Chi Soft Ball, Taiji Soft Ball, Rouliqiu, Tai Chi Rouliqiu, Taiji Rouliqiu, Tai Chi Bailong Ball, Tai Chi Bailong Ball); 四) 兩位研究員分 別審閲了符合條件的文獻摘要, 並商討各文獻的相關性。結 果沒有國際性文獻直接談論太極柔力球運動產生的中國歷史 文化背景。於八個國際論文集數據庫中, 作者只找到 兩篇文章間接地提及太極柔力球的中國歷史文化背景 (Lam et al., 201la \& Lam et al., 2011b)。 雖然中 國內地有少數文獻曾提及過太極柔力球的中國歷史文化背 景, 但世界學術界對此方面的研究仍未起步。為了進一步探 討該項有中國特色的運動對中西文化交流的影響, 有必要對 其產生的中國歷史文化背景進行深入的研究。

\section{參考文獻}

Lam, Michael. H. S., Cheung, S.Y., \& Chow, B.C. (2011a). Tai-Chi Soft-Ball Training on Physical Functional Health of Chinese Older Adults with Functional Limitations. Journal of Human Sport and Exercise, 6(3), 540-553.

Lam, Michael. H. S., Cheung, S.Y., \& Chow, B.C. (2011b). Effects of Tai Chi Soft Ball Training on Health Related Quality of Life of Older Adult with Functional Limitations. Asian Journal of Gerontology and Geriatrics, 6(3), 22-34

全國體育院校教材委員會，武術(上冊)，北京：人民體育出版 社, 1991, 6.
太極拳全書(修訂版)，北京:人民體育出版社，1995，7. 馬虹. 陳式太極拳拳法拳理．北京:北京體育大學出版 社, 2003, 1.

李恩荊等太太極柔力球與小球運動。武漢：華中師範大學出 版社, 2007, 4.

王斌。道教文化與中國傳統體育。北京體育大學學報, 2004, 27(1):33-34.

馬啟偉．從哲學和社會科學視角認識體育運動。體育科學, 2002, 7(3):40-43.

宋繼新．科學與人文融合的競技教育．北京體育大學學報， 2002, 25(6):721-726.

\section{通訊作者}

姓名:林絢琛

地址: 香港薄扶林沙宣道21號醫學院蒙民偉樓四樓

電郵 : michaelpublicaffair@gmail.com

電話: (852) 65423388 